\title{
PLATAFORMAS DE DESCUBRIMIENTO EN BIBLIOTECAS UNIVERSITARIAS: EVALUACIÓN DE WORLDCAT LOCAL EN EL CONTEXTO DE UNA BIBLIOTECA CARIBEÑA
}

\author{
Marilyn Montalvo Montalvo* \\ Sistema de Bibliotecas. Recinto de Río Piedras. Universidad de Puerto Rico.
}

\begin{abstract}
Resumen: Se presenta una evaluación amplia de WorldCat Local (WCL), a la luz de su implementación en el Sistema de Bibliotecas de la Universidad de Puerto Rico en Río Piedras (SB). Primeramente, se realiza una descripción detallada de su estructura, alcance, proceso de configuración e interfaz de búsqueda para explorar cómo sus rasgos inciden en la experiencia de descubrimiento. En segundo lugar, se ofrecen los resultados de un sondeo realizado entre la comunidad universitaria para conocer su opinión sobre el metabuscador. Se concluye que, si bien WCL no ha llenado las expectativas del SB desde la óptica administrativa, los usuarios valoran la disponibilidad de una herramienta que les permita agilizar la búsqueda de información.

Palabras clave: plataformas de descubrimiento; herramientas de descubrimiento; metabuscadores; evaluación de plataformas de descubrimiento; bibliotecas universitarias; Caribe; Puerto Rico; WorldCat Local.
\end{abstract}

\begin{abstract}
Title: DISCOVERY TOOLS IN ACADEMIC LIBRARIES: AN EVALUATION OF WORLDCAT LOCAL IN A CARIBBEAN LIBRARY CONTEXT.

Abstract: A thorough assessment of WorldCat Local (WCL) is presented, in light of its implementation at the Library System of the University of Puerto Rico in Rio Piedras (LS). First, a description of its structure, content coverage, configuration process and search interface is provided, in order to explore their impact on the discovery experience. Second, the results of a survey conducted among the academic community to find out its views about the discovery tool are offered. It is concluded that, although WCL has not fulfilled the expectations of the LS from an administrative perspective, users value the availability of a tool that allows them to speed up information search. Keywords: WorldCat Local; discovery tools; evaluation of discovery tools; Caribbean Area; academic libraries.
\end{abstract}

Copyright: () 2017 Servicio de Publicaciones de la Universidad de Murcia (Spain). Este es un artículo de acceso abierto distribuido bajo los términos de la licencia Creative Commons Reconocimiento 4.0 Internacional (CC BY 4.0).

\section{ESTADO DE LA CUESTIÓN}

El crecimiento y la diversificación de los recursos informativos en soporte electrónico han supuesto un gran adelanto para el acceso a la información. Además, los recursos digitales se conjugan con los catálogos en línea para mostrar toda la riqueza de los acervos bibliográficos de las bibliotecas. Sin embargo, el desarrollo de motores de búsqueda, tales como Google Scholar, en combinación con la digitalización masiva de documentos de acceso abierto, con gran visibilidad en internet, están generando usuarios que buscan la conveniencia de los sistemas llamados 'amigables' y que esperan encontrar de inmediato la información deseada, tecleando una o varias palabras más o menos relacionadas, sin intentar construir parámetros de búsqueda que les permitan mejorar la relevancia de los resultados (Spink et al., 2001; Badke, 2014; Georgas, 2014; Strykowsky, 2015). En la actualidad, las bibliotecas universitarias compiten por el favor de sus usuarios universitarios mediante la divulgación de sus recursos informativos electrónicos en clases de capacitación y desde sus páginas web. No obstante, a medida que aumentan y se diversifican las colecciones digitales, los usuarios muestran su desconcierto ante la necesidad de hacer múltiples búsquedas en diversas fuentes de información y los bibliotecarios ven con impotencia cómo estudiantes y profesores emigran a Google, donde pueden encontrar cantidades ingentes de información mediante una búsqueda básica (Parry, 2014; Connaway y Randall, 2013).

La desiderata de los usuarios de acceder a todos los recursos de información desde una interfaz de búsqueda común o una 'ventanilla única', ha sido el motor para la elaboración de herramientas que simplifiquen la búsqueda de información en las colecciones de las bibliotecas, no solamente en recursos electrónicos de pago, sino en catálogos en línea y repositorios de investigación (Alvite Díez, 2012; Ávila García, Ortiz Repiso y Rodríguez Mateos, 2015; Prescott y Erway, 2011). Así, desde finales de los años noventa se han estado desarrollando productos que permiten realizar búsquedas simultáneas en diferentes bases de datos. Los primeros metabuscadores, o interfaces de

*marilyn.montalvo1@upr.edu

Recibido: 16-06-2016; 2 versión: 05-04-2017; aceptado: 10-04-2017.

MONTALVO MONTALVO, M. Plataformas de descubrimiento en bibliotecas universitarias: evaluación de WorldCat Local en el contexto de una biblioteca caribeña. Anales de Documentación, 2017, vol. 20, $\mathrm{n}^{\circ} 2 . \quad$ Disponible en: http://dx.doi.org/10.6018/analesdoc.20.2.261381. 
descubrimiento, se valían del protocolo Z39.50 para hacer búsquedas en tiempo real, también conocidas como 'búsquedas federadas' (Boyd et al., 2006; King, 2008). La eficacia de estas herramientas dependía, en gran parte, de la infraestructura de telecomunicaciones de las bases de datos a las que accedían. En la práctica, pronto se comprobó que no tenían la rapidez necesaria y que la relevancia de los resultados tampoco era la esperada (Tenant, 2003; Herrera, 2007).

Para superar estas limitaciones, a partir del 2007 los metabuscadores se alejan de las búsquedas federadas y surgen productos que incorporan la información bibliográfica provista por los editores y otros proveedores de contenidos en un índice central. La ventaja de estos productos, también denominados herramientas, plataformas o servicios de descubrimiento a escala web, es que las empresas dedicadas a su desarrollo disponen de millones de registros bibliográficos, provistos por los dueños de los contenidos y sus distribuidores, que indexan en sus propios servidores, según acuerdos negociados. Además de reducir o eliminar las búsquedas en tiempo real, estos productos también tienen la capacidad de incorporar el acceso a catálogos en línea y repositorios de investigación (Breeding, 2014; Popp y Dallis, 2012; Vaughan, 2011). Entre los metabuscadores que comparten estas características se destacan EDS (Ebsco), Primo (ExLibris), Summon (Proquest) y WorldCat Local (OCLC).

El alcance y la eficacia de las plataformas de descubrimiento están condicionados por diversos factores. En primer lugar, no todos los distribuidores de contenidos, ni todos los proveedores de servicios de indexación están dispuestos a incluir su metadata, ya sea la totalidad o una parte, en los índices centrales de las plataformas de descubrimiento. Esta reticencia obedece a diversas razones. Por una parte, existe rivalidad entre proveedores de metabuscadores que también son distribuidores de contenidos. Por otra, algunos distribuidores y proveedores de contenidos desconfían de la prelación que tendrán sus productos en los resultados de las búsquedas, de la identificación inequívoca de la procedencia de la información bibliográfica o los textos recuperados y de la precisión de las estadísticas de uso provistas por las plataformas de descubrimiento. En el caso específico de los índices que no contienen texto completo, algunos proveedores temen que su trabajo de indexación pierda valor si se integra con bases de datos que sí lo proveen (Kelley, 2012; NFAIS, 2014). Como resultado, ninguna plataforma puede descubrir todos los recursos informativos electrónicos que suscribe o adquiere una biblioteca.

En segundo lugar, la eficacia de los metabuscadores también depende de que los componentes tecnológicos que se esconden tras bastidores, entre los que se destacan el Open URL, el Link Resolver y el Knowledge Base (KB), funcionen coordinadamente (Trainor y Price, 2010; Glasser, 2011). Estos tres componentes permiten construir URLs que identifiquen correctamente los contenidos, determinar cuáles suscribe la biblioteca y acceder al texto completo. En tercer lugar, ya que el proceso de indexación de los registros bibliográficos se realiza paulatinamente, siempre habrá discrepancias entre los recursos suscritos o adquiridos por las bibliotecas y los que ya están incluidos en el índice central. En cuarto lugar, la corrección, normalización y riqueza de la metadata enviada por los proveedores de contenidos al índice central del metabuscador serán decisivas para que las búsquedas realizadas sean efectivas. Hay que tener presente que esta información no se codifica en formato MARC, sino utilizando diversos esquemas, entre los cuales puede haber un mayor o menor grado de compatibilidad (NISO, 2004; Brand, Daly y Meyers, 2003).

Finalmente, para que el administrador del metabuscador pueda configurarlo correctamente, debe conocer los datos particulares de los recursos suscritos o adquiridos a perpetuidad, tales como, el nombre específico de las colecciones, los títulos adquiridos individualmente y los proveedores de cada producto. En el caso de las bases de datos provistas por distribuidores, debe estar atento a los cambios que puedan surgir en las negociaciones que realizan los distribuidores y propietarios de contenidos.

Todas las plataformas de descubrimiento tienen características que las asemejan o diferencian, al igual que fortalezas y debilidades (Vaughan, 2011; Goodset, 2014). Debido a la complejidad que entrañan, las bibliotecas se han acercado a estos productos de diversas formas. Algunas han hecho intentos de evaluar a fondo sus prestaciones antes de suscribirlos; otras los han adoptado durante su etapa inicial de desarrollo, mediante acuerdos de colaboración realizados con sus respectivos proveedores; y otras han confiado en los prospectos de los productos y en las demostraciones ofrecidas por sus vendedores (Cornell, 2011; Butler y Thompson, 2013).

Como cabe esperar, la herramienta que se oculta detrás de la `ventanilla única tiene sus detractores y defensores. Muchos bibliotecarios se niegan a promover los metabuscadores en sus clases de capacitación porque creen que estas herramientas no ayudan a los usuarios a desarrollar destrezas de búsqueda y prefieren enseñarles a buscar directamente en cada base de datos. Otros consideran que las plataformas de descubrimiento son herramientas útiles para hacer búsquedas simultáneas en diversos recursos electrónicos, especialmente en aquellos que carecen de la necesaria visibilidad (Fawley y Krysak, 2014; Kulp, McCain y Scrivener, 2014). Según la información aportada por bibliotecas de todo el mundo a Libraries.org (Breeding, 2016), las bibliotecas continúan suscribiendo metabuscadores. Muchas, 
incluso, ya han cambiado de plataforma, lo que podría constituir un indicador de la insatisfacción existente y de lo difícil que resulta anticipar el comportamiento de productos tan complejos (Dartmouth, 2009). Los usuarios, sin embargo, parecen apreciar la disponibilidad de una herramienta que los ayude a encontrar información en las bibliotecas y no parece que perciban diferencias significativas entre un metabuscador y otro (Georgas, 2013; Djenno et al., 2014).

\section{PROPÓSITO Y METODOLOGÍA}

El propósito de este trabajo es evaluar la plataforma de descubrimiento WorldCat Local (WCL) a la luz de su implementación en el Sistema de Bibliotecas de la Universidad de Puerto Rico en Río Piedras (SB). ${ }^{1}$ Teniendo en cuenta que los metabuscadores son herramientas muy complejas, la evaluación de WCL se abordará desde una perspectiva amplia.

Primeramente, se realizará una descripción detallada de la estructura de WCL, del alcance de los contenidos que permite descubrir, del proceso de configuración y de la interfaz de búsqueda para explorar cómo sus rasgos más característicos inciden en la experiencia de descubrimiento. En segundo lugar, se ofrecerán los resultados de un sondeo realizado entre la comunidad universitaria a la que presta servicios el SB para conocer si el metabuscador satisface las expectativas de los usuarios.

\section{ANTECEDENTES}

El SB ha experimentado, al igual que otras bibliotecas universitarias, un aumento importante de sus recursos informativos en soporte electrónico. Desde el año 2000, ha enriquecido su acervo de publicaciones electrónicas, tanto en cantidad como en diversidad. Actualmente, suscribe más de 150 productos provistos, tanto por distribuidores como por editores, que incluyen información en diversos formatos. Los productos, en su conjunto, se conocen como 'bases de datos'. Aunque predominan las revistas, también se suscriben o adquieren a perpetuidad libros, enciclopedias, diccionarios, documentos gubernamentales, periódicos, imágenes, videos y partituras. Todos los productos tienen algunos contenidos únicos pero hay un porcentaje alto de duplicación, ya que muchos recursos solamente están disponibles en paquetes cerrados. Las bases de datos se acceden desde el campus de Río Piedras y el acceso remoto se ofrece a los estudiantes y empleados activos, mediante autentificación. Su administración está a cargo del bibliotecario Coordinador del Programa de Automatización, a quien le corresponde gestionar la configuración, acceso, divulgación y recopilación de las estadísticas de uso.

Las bases de datos suscritas por el SB no se catalogan. La inseguridad existente con respecto a la renovación de los productos, la premura impuesta por la necesidad de ofrecer acceso inmediato, la complejidad de la catalogación de los recursos electrónicos, la calidad de los registros MARC elaborados por los distribuidores o proveedores de contenidos y la inestabilidad de los hipervínculos, no han favorecido su inclusión en el catálogo en línea del SB. Desde que comenzó el desarrollo de colecciones de recursos electrónicos, se ha establecido la política de catalogar solamente los ebooks adquiridos con acceso perpetuo y ofrecer el acceso a los demás contenidos mediante listas alfabéticas y temáticas que se colocan en la página web del SB. Las listas y sus respectivos enlaces se revisan y actualizan constantemente para garantizar el acceso a los recursos. A medida que la cantidad de recursos electrónicos ha aumentado y se ha diversificado, el proceso de búsqueda de información también se ha hecho más complicado, ya que los usuarios deben acceder individualmente a cada una de las bases de datos y familiarizarse con diferentes plataformas y opciones de búsqueda. Además, el distanciamiento entre el catálogo en línea y los recursos electrónicos aleja cada vez más a los usuarios del acervo bibliográfico tangible, que aún sigue siendo el mayor.

La divulgación de las bases de datos y el catálogo en línea se realiza, principalmente, mediante clases de capacitación que se ofrecen a los usuarios, especialmente a los estudiantes. En cada sesión los bibliotecarios ofrecen una visión panorámica de los recursos disponibles, presentan información detallada de algunos de los contenidos y destacan las opciones de búsqueda comunes a todas las plataformas con el fin de enseñarles a los usuarios las destrezas de búsqueda de información necesarias para obtener resultados relevantes. Sin embargo, el alcance de las clases ofrecidas es muy limitado. Además, muchos de los estudiantes no reciben la información cuando verdaderamente la necesitan. Los profesores también desconocen la existencia de gran parte del acervo bibliográfico disponible en soporte electrónico en el SB y no existe un plan de capacitación para la facultad. Los recursos electrónicos también se divulgan mediante tutoriales, a los que se puede acceder desde la página web del SB.

Las estadísticas de uso generadas por cada base de datos reflejan miles de búsquedas y, en algunos casos, hasta superan el millón. Sin embargo, es probable que algunos datos estén inflados, a juzgar por los usuarios que acuden al 
Programa de Automatización porque no pueden acceder al texto completo de alguna publicación que encontraron a través de una búsqueda en Google, porque preguntan cómo acceder "a la base de datos del SB", como si se tratara de un solo producto, o bien porque no pueden o no saben cómo autentificarse para obtener acceso remoto.

Conscientes de las dificultades que encuentran los usuarios para navegar por los diferentes recursos electrónicos suscritos y de las limitaciones existentes para su divulgación, un grupo de bibliotecarios de la Universidad de Puerto Rico recomendó en 2007 la suscripción en consorcio del metabuscador Central Search de Proquest. Este producto, que hacía búsquedas federadas en el catálogo en línea y en algunas de las bases de datos suscritas, utilizando el protocolo Z39.50, funcionaba adecuadamente para hacer búsquedas simultáneas en catálogos en línea, cuyos registros bibliográficos, codificados en formato MARC, permitían obtener resultados relevantes. Sin embargo, no podía responder de la misma forma a la hora de recuperar recursos electrónicos provenientes de distintas plataformas comerciales, cuya metadata no ofrecía el mismo grado de normalización. Además, la búsqueda federada en cada una de las bases de datos era muy lenta. Por tratarse de una plataforma suscrita de forma consorciada, solamente incluía las bases de datos suscritas en común por las bibliotecas y no era administrada por personal del SB. Por estas razones, la suscripción de Central Search se canceló en 2011.

A comienzos de 2012 ya estaban disponibles en el mercado varias nuevas plataformas de descubrimiento. Estas herramientas disponían de una estructura diferente, basada en el desarrollo de un gran índice central, que prometía mayor eficacia. Eran herramientas costosas, cuya estructura se desconocía. El primer producto que se consideró fue EDS, de Ebsco, ya que el SB suscribe desde hace muchos años diversas bases de datos de la plataforma Ebsco Host Research Databases, un producto, cuya calidad es indiscutible. También suscribe Ebsco A-Z, una herramienta que se utiliza como metabuscador de las revistas incluidas en las diversas bases de datos suscritas. Además, Ebsco ha sido durante muchos años el gestor de suscripciones de revistas del SB. Sin embargo, EDS se tuvo que descartar por varias razones. Primeramente, era muy costoso, ya que el precio del metabuscador incluía un número limitado de bases de datos y cada producto adicional se facturaba aparte. En segundo lugar, EDS no mantenía acuerdos con Proquest ni Gale-Cengage. En tercer lugar, se temía que se produjera una cierta parcialidad a favor de las bases de datos distribuidas por Ebsco. En cuarto lugar, la inclusión del catálogo en línea también tenía un costo adicional y su incorporación a EDS se realizaría con OCLC como intermediario, algo que lucía bastante complicado e incierto.

El segundo producto que se evaluó fue WorldCat Local (WCL). Teniendo en cuenta que el SB ha formado parte del consorcio de OCLC desde los años ochenta, aporta sistemáticamente la catalogación de sus recursos informativos a WorldCat (WC), participa de su programa de préstamos interbibliotecarios, suscribe la versión de pago de WC y utiliza CONTENTdm, su plataforma para el desarrollo de repositorios de investigación, WCL parecía una opción lógica. Además, WCL presentaba varias ventajas con respecto a EDS. Primeramente, siendo OCLC una organización sin fines de lucro que no rivaliza con los grandes distribuidores de contenidos, WCL se presentaba como una herramienta de descubrimiento neutral que mantenía acuerdos con una amplia lista de proveedores, entre los que se incluían Ebsco, Gale-Cengage y Proquest. En segundo lugar, ya tenía incorporado el acceso a los registros bibliográficos de los recursos catalogados por el SB y por todas las bibliotecas que aportan su catalogación a WC. En tercer lugar, el precio de WCL era menor y permitía configurar un número ilimitado de bases de datos sin costo adicional. Por estas razones, se decidió optar por WCL.

Se examinaron diversos prospectos de WCL, se solicitaron demostraciones y se sostuvieron reuniones con representantes de OCLC para tener una idea clara de la estructura y del proceso de implementación del metabuscador. Se determinó que, para decidir si WCL era realmente la mejor opción para el SB, era necesario configurar un número significativo de las bases de datos suscritas y comprobar su funcionamiento. A finales de junio de 2012 se solicitó un período de prueba de seis meses con full implementation que permitiría configurar la herramienta, darla a conocer y evaluarla.

\section{ESTRUCTURA Y ALCANCE DE WORLDCAT LOCAL}

Para comprender la estructura de WCL hay que familiarizarse con WorldCat, ya que esta base de datos es la médula de los productos y servicios de OCLC. WC contiene los registros de los recursos bibliográficos de las instituciones que aportan su catalogación original al consorcio y también refleja los ejemplares (holdings) de aquellos recursos vinculados a un registro bibliográfico maestro. WC también dispone de una versión gratuita, que aumenta la visibilidad en internet del acervo bibliográfico de las instituciones que forman parte del consorcio de catalogación de OCLC. WCL añade a estos servicios un índice central en el que se almacena la metadata de miles de bases de datos con cuyos proveedores OCLC tiene algún tipo de acuerdo, así como la posibilidad de configurar los repositorios de investigación que han sido desarrollados utilizando CONTENTdm, su plataforma digital. Además, permite descubrir 
miles de documentos depositados en repositorios desarrollados con el Open Archives Initiative Protocol for Metadata Harvesting (OAI-PMH) a través de OAISTER, un catálogo colectivo elaborado por OCLC.

La estructura que permite convertir a WCL en una herramienta de descubrimiento depende de cuatro componentes principales: WC, que contiene más de trescientos millones de registros bibliográficos aportados por las instituciones que pertenecen al consorcio de OCLC; el índice central, donde se almacena la metadata enviada periódicamente por los proveedores de contenidos; el estándar Z39.50, que permite hacer búsquedas federadas; y el Knowledge Base (KB), que contiene información sobre las colecciones completas o títulos individuales incluidos en WCL y que permite activar el acceso a los productos específicos suscritos o adquiridos con acceso perpetuo. El envío y la incorporación de la metadata al índice central se realizan paulatinamente, por lo que la disponibilidad de los contenidos no es inmediata.

WCL está diseñado para que los usuarios puedan elegir las bases de datos de su preferencia en la interfaz de búsqueda. Sin embargo, hay proveedores que no permiten que sus productos se configuren de forma discreta. En estos casos, no es posible identificarlos, ya que sus contenidos están englobados en el índice central. Por otra parte, no todos los proveedores con los cuales OCLC mantiene acuerdos envían la metadata de sus contenidos. El acceso a estos productos se provee mediante el estándar Z39.50, lo que convierte a WCL en un metabuscador híbrido. Aunque WCL permite hacer búsquedas desde fuera del campus universitario sin necesidad de autentificarse, siempre y cuando no se intente acceder a los contenidos, los productos que requieren búsquedas federadas disparan automáticamente el protocolo de acceso remoto.

OCLC publica y actualiza periódicamente en su página web diversos documentos que describen detalladamente los procesos de configuración de WCL. Además, publica dos listas, denominadas respectivamente, Content available through WorldCat Discovery y Collections available in the WorldCat knowledge base, en las que se ofrecen datos sobre las bases de datos incluidas, tales como, el porcentaje de cobertura de cada una y el tipo de acceso disponible (OCLC 2016a, 2016b). Sin embargo, la información incluida en estas listas no permite determinar el alcance real del metabuscador porque no se clarifica la diferencia entre 'contents' y 'collections' ni se explica por qué en un documento hay más de 14000 productos y en el otro alrededor de mil. Además, los porcentajes incluidos no permiten conocer la cantidad de títulos específicos incluidos. En el caso de las bases de datos que se acceden mediante búsquedas federadas, las listas indican que tienen una cobertura del 100\%, pero es importante tener en cuenta que estos productos no están incluidos en el índice central y que la eficacia de las búsquedas en tiempo real dependerá de la rapidez de respuesta de cada uno. Hay que destacar que la diferencia entre WC, el índice central y el KB no es transparente, como tampoco lo es el uso de nomenclatura similar para identificar diferentes servicios derivados de WC (WorldCat, WorldCat Local, WorldCat Discovery, WorldCat.org, Worldshare Management).

La sincronización del catálogo en línea con WCL requiere que la biblioteca aporte a WC su catalogación original y vincule sus registros de ejemplares con los registros bibliográficos aportados por otras bibliotecas. Además, los registros bibliográficos que residen en el sistema de gestión de la biblioteca deben contener el número de OCLC en el campo MARC 035, ya que WCL se conecta con el catálogo en línea por medio de este número para mostrar los ejemplares disponibles y su ubicación. La exactitud con la que WCL refleje el acervo del catálogo de la biblioteca dependerá de que haya un pareo exacto entre los registros incluidos en ambos. Es importante aclarar que los registros bibliográficos que verá el usuario en WCL serán los registros aportados a WC por las bibliotecas que proveyeron la catalogación original, por lo que podría haber discrepancias entre la metadata de estos registros y los del catálogo de la biblioteca.

WCL dispone de algoritmos de relevancia que les dan peso a los campos de autor, título y tema, a la proximidad de los términos utilizados en las búsquedas, a la fecha de publicación y a la cantidad de instituciones del consorcio de OCLC que posee el recurso. La relevancia de los resultados también depende de que la metadata resida en el índice central o de que WCL tenga que realizar una búsqueda federada en las bases de datos seleccionadas. En este último caso, el metabuscador mostrará los resultados recuperados en treinta segundos y, tanto la cantidad de resultados como su relevancia, dependerán de la rapidez con la que WCL haya podido hacer las búsquedas y organizar los resultados.

\section{CONFIGURACIÓN DE WORLDCAT LOCAL}

La dirección del SB determinó que la gestión de WCL estuviera a cargo del Coordinador del Programa de Automatización del SB. La experiencia como gestor de las bases de datos suscritas y el metabuscador de revistas, Ebsco A-Z, así como el conocimiento de la estructura de WC, le aportaron información útil para iniciar el proceso de configuración. 
La inclusión del catálogo en línea del SB en WCL se hizo de forma casi automática porque la mayor parte del acervo bibliográfico tangible del SB ya figuraba en WC. La configuración requirió incluir en el OPAC del SB un índice de Utilitynumber entre las opciones de búsqueda. El Utilitynumber, que corresponde al número de OCLC que aparece en el campo 035 del registro MARC, permitió la conexión de la información bibliográfica incluida en WCL con el catálogo del SB para mostrar en tiempo real la ubicación y disponibilidad de los ejemplares de cada título catalogado. Sin embargo, al realizar las primeras búsquedas se comprobó que había ciertas discrepancias entre la información reflejada en WC y el OPAC del SB, debido a que la información incluida en WC no estaba completamente actualizada. Por una parte, un porcentaje indeterminado de ejemplares nunca se había añadido a WC o aparecía en WC pero ya no estaba disponible en el SB. Por otra, el número de OCLC, esencial para identificar las existencias, no era privativo de los registros bibliográficos del SB, ya que muchas de las bibliotecas de otros recintos de la Universidad de Puerto Rico que comparten la misma base de datos bibliográficos con el SB, mantienen el número de OCLC en los registros que utilizan como parte de los procesos de catalogación derivada. Al encontrar más de un registro con el mismo número de OCLC, WCL no podía hacer el pareo necesario y arrojaba resultados confusos o mensajes de error. Aunque OCLC provee opciones para actualizar y conciliar en bloque los registros de la biblioteca, mientras el SB compartiera su base de datos con otras bibliotecas de la UPR, los problemas creados por la duplicación del número de OCLC persistirían. Por esta razón, se decidió aceptar las limitaciones encontradas en la recuperación del catálogo en línea.

La configuración de OAISTER y de la Biblioteca Digital del SB desarrollada con la plataforma de CONTENTdm, solamente requirió activar los parámetros correspondientes a cada uno en el módulo administrativo. La compatibilidad de WCL con estos productos permitió el acceso a cientos de repositorios de investigación y a los documentos puertorriqueños que se digitalizan e indizan utilizando CONTENTdm. La configuración de las bases de datos de pago fue más complicada. El proceso requirió que se configuraran en Pubget, en el Knowledge Base y en el Metasearch Content. La configuración en Pubget fue necesaria para seleccionar los proveedores cuyos productos la biblioteca suscribe y llevar constancia de la periodicidad con la que envían la metadata de sus contenidos al índice central. La selección en el Knowledge Base de las bases de datos suscritas y los ebooks adquiridos individualmente fue necesaria para poder acceder a sus contenidos. El Metasearch Content se configuró para que WCL mostrara en la interfaz de búsqueda aquellos productos cuyos proveedores permiten que se busquen individualmente.

Durante el proceso de configuración se comenzaron a hacer pruebas aleatorias para corroborar si el metabuscador localizaba, al menos, alguno de los recursos incluidos en cada una de las bases de datos configuradas, especialmente aquellos contenidos cuya metadata suele estar menos normalizada o cuya estructura puede impedir su recuperación. En especial, se hicieron búsquedas de registros específicos de videos, tesis, imágenes, documentos gubernamentales, diccionarios y enciclopedias. Las pruebas realizadas demostraron que los resultados no incluían los videos de Alexander Street Press, las tesis de Proquest Dissertations and Theses, los documentos del U.S. Serial Set, información de la enciclopedia Britannica, ni algunos ebooks de Ebrary y Gale Virtual Reference Library. Teniendo en cuenta que estos productos figuraban en las listas de acuerdos negociados, resultaba sorprendente que WCL no estuviese descubriendo sus contenidos. Las primeras pruebas también arrojaron una cantidad de registros muy inferior a la que se obtenía al buscar directamente en cada base de datos. Los problemas encontrados se debían, principalmente, a que los registros aún no habían sido incluidos en el índice central, a problemas estructurales de WCL que no permitían recuperar algunos formatos, a problemas derivados de las búsquedas federadas y a errores en la metadata o en los resolutores de enlaces provistos por editores y distribuidores. En el caso específico de los ebooks adquiridos a través de Ebrary, la tarea se pudo simplificar porque se podían añadir automáticamente, como parte del proceso de compra, gracias a un acuerdo entre Proquest y OCLC.

La imposibilidad de configurar en el Metasearch Content todas las bases de datos como productos discretos constituyó una limitación importante, toda vez que parecía que la biblioteca solamente suscribía aquellos productos que aparecían visibles en la interfaz de búsqueda. La integración en WCL de bases de datos cuya metadata reside en el índice central con otras que se acceden por medio del protocolo Z39.50 es una de las características de la estructura del metabuscador que incide en su efectividad. Tanto si se configuran por defecto en el Metasearch Content todas las bases de datos que se pueden destacar como productos independientes, como si se deja que el usuario las seleccione en una búsqueda avanzada, WCL las busca simultáneamente en el índice central o realiza una búsqueda federada, dependiendo del tipo de acceso provisto para cada una. Para evitar que el sistema se recargue con las búsquedas federadas, WCL busca durante treinta segundos, al cabo de los cuales muestra los resultados encontrados en las bases de datos, el índice central, WC y OAISTER. Inicialmente, se configuraron por defecto todas las bases de datos disponibles en el Metasearch Content, pero pronto se comprobó que la relevancia de los resultados disminuía y que la plataforma respondía erráticamente. Para solucionar este problema, el personal de OCLC recomendaba configurar por defecto solamente WC y OAISTER, pero esta opción les restaba visibilidad a las demás bases de datos, ya que habría 
que seleccionarlas en una búsqueda avanzada. Ante esta situación, se optó por configurar por defecto algunas de las bases de datos que más se deseaban destacar y dejar que el usuario seleccionara las demás, a pesar de la subjetividad que esta decisión suponía.

Para visualizar el alcance real de WCL fue necesario elaborar listas de cotejo en las que se agrupaban las bases de datos según su tipo de acceso dentro de la estructura de la plataforma y realizar pruebas específicas para verificar que los resultados respondían a los acuerdos negociados con los proveedores. En el caso de las bases de datos que no podían configurarse como productos discretos, era mucho más difícil determinar si WCL estaba descubriendo sus contenidos. Por otra parte, se comenzaron a documentar y a notificar a OCLC todas las lagunas encontradas. Este proceso de control de calidad fue esencial para mejorar los resultados de las búsquedas. No obstante, hubo problemas que no pudieron resolverse. A pesar de que todas las peticiones iban acompañadas de ejemplos, el personal de apoyo técnico no siempre comprendía la naturaleza de los planteamientos. En otros casos, se trataba de limitaciones que no tenían solución inmediata porque conllevaban cambios en la programación de WCL.

Hay que destacar que solamente se configuraron las revistas suscritas como colecciones porque todas las revistas ya se habían configurado en el metabuscador de revistas, Ebsco A-Z. Configurar nuevamente miles de revistas supondría duplicar esfuerzos. Además, había que considerar que la suscripción de Ebsco A-Z prevalecería, en caso de tener que cancelar alguno de los dos productos, ya que su costo era mucho menor.

El proceso de configuración de WCL abarcó todo el período de prueba, al cabo del cual se formalizó la suscripción. De un total de 171 bases de datos suscritas, se pudieron configurar 109 en el Knowledge Base y 61 en el Metasearch Content. A partir de febrero de 2013, WCL se comenzó a divulgar en la sección de Búsqueda Rápida de la página web del SB como 'Metabuscador de bases de datos', ya que a EBSCO A-Z se le conocía como 'Metabuscador de revistas'. Durante los meses subsiguientes, la administración de WCL se convirtió una de las tareas principales del Coordinador del Programa de Automatización.

\section{LA INTERFAZ DE BÚSQUEDA DE WCL}

La estructura de WCL se traduce en una plataforma de descubrimiento singular que está diseñada para que el usuario elija entre varias opciones de búsqueda, algunas de las cuales son producto del tipo de configuración realizada por el administrador de la plataforma. Se puede buscar simultáneamente en los catálogos de todas las bibliotecas que aportan sus registros bibliográficos a WC, en los catálogos de las bibliotecas de un consorcio o solamente en el catálogo de la biblioteca que suscribe el metabuscador. Si se selecciona la primera opción, WCL también buscará en el índice central y en OAISTER. Si se elige la segunda o la tercera, buscará solamente los registros bibliográficos de las bibliotecas seleccionadas. Por otra parte, si el usuario opta por la búsqueda básica, obtendrá resultados de las bases de datos que han sido configuradas por defecto por el administrador de WCL. Si opta por la búsqueda avanzada, podrá elegir entre todos los productos configurados. Cabe destacar que los usuarios desconocen que muchas bases de datos no ofrecen esta opción.

Si el usuario selecciona algún producto que no figura en el índice central, tendrá que autentificarse antes de hacer las búsquedas. Además, notará que la búsqueda se ralentizará y al cabo de treinta segundos WCL mostrará solamente los resultados recuperados hasta ese momento. A mayor cantidad de bases de datos seleccionadas, menor será la efectividad de la plataforma y más errático su comportamiento, hasta tal punto, que puede dejar de funcionar.

La relevancia de los resultados obtenidos por WCL está determinada por una compleja combinación de algoritmos que los usuarios desconocen. La relevancia de los resultados procedentes de WC suele ser alta, pero puede disminuir, notablemente, si WC se excluye de las búsquedas. La relevancia de los resultados de los productos que se acceden mediante búsquedas federadas depende de la rapidez de respuesta de cada base de datos. WCL permite establecer el orden de los resultados por relevancia o biblioteca y relevancia, pero si se elige la segunda opción, primará la biblioteca y la relevancia tendrá menor peso. Los resultados de las búsquedas también se pueden organizar por base de datos, formato, tema y nombres personales.

Otra de las características notables de la interfaz de búsqueda de WCL es que si el texto completo está disponible en más de una bases de datos, los muestra todos e indica la procedencia de cada uno. WCL también cuenta con un mecanismo de consolidación de registros duplicados, pero no siempre es efectivo. La disponibilidad de los textos completos se destaca con un enlace denominado View now, que aparece junto a los resultados. WCL no está exento de enlaces rotos. Dependiendo de la procedencia de los contenidos, es posible obtener resultados en los que todos los enlaces abren correctamente y otras en las que los enlaces rotos abundan. Hay que destacar que, aunque no aparezca el 
View now en la versión abreviada del registro bibliográfico, en ocasiones se encuentra un enlace al texto completo en la versión detallada.

La interfaz de búsqueda de WCL ofrece diversas opciones de valor añadido. Permite elaborar citas bibliográficas según diversos estilos y guardar las búsquedas realizadas, así como añadir reseñas y etiquetas a los resultados. WCL también muestra, de forma organizada, las diferentes ediciones y formatos de los recursos informativos encontrados en WC, como parte de la 'FRBRización' de los registros bibliográficos aportados por más de 70000 instituciones participantes. Asimismo, permite conocer el perfil bibliográfico de los autores incluidos en WC, mediante un enlace con Identities, otro proyecto de OCLC. Además, WCL genera automáticamente una lista A-Z de las revistas y los ebooks configurados, muy útil para buscar de forma más directa, títulos o artículos específicos. Finalmente, cabe destacar que el administrador de la plataforma puede añadir a la interfaz diversos enlaces de interés para los usuarios.

\section{EVALUACIÓN DE LA ESTRUCTURA, ALCANCE, CONFIGURACIÓN E INTERFAZ DE BÚSQUEDA DE WCL}

Para sopesar el comportamiento de WCL en el entorno del SB, desde el punto de vista de su gestión, se seleccionaron veintidós de las características de su estructura que más inciden en su eficacia y se clasificaron en dos grupos: fortalezas o debilidades intrínsecas y fortalezas o debilidades aplicables a la experiencia particular del SB. Según la clasificación realizada, el $64 \%$ de los rasgos examinados pueden considerarse fortalezas intrínsecas de la plataforma, pero en el contexto específico del SB, el 59\% de los rasgos constituyen debilidades, entre las que se destacan, un laborioso proceso de configuración, limitaciones en cuanto al alcance real y una experiencia de descubrimiento incompleta o confusa (Ver Tabla 1).

\begin{tabular}{|c|c|c|c|c|}
\hline RASGO & $\begin{array}{l}\text { FORTALEZA } \\
\text { INTRÍNSECA }\end{array}$ & $\begin{array}{l}\text { DEBILIDAD } \\
\text { INTRÍNSECA }\end{array}$ & $\begin{array}{ll}\text { FORTALECE } & \text { LA } \\
\text { EXPERIENCIA } & \text { DE } \\
\text { DESCUBRIMIENTO } \\
\text { EN EL SB }\end{array}$ & $\begin{array}{ll}\text { DEBILITA } & \text { LA } \\
\text { EXPERIENCIA } & \text { DE } \\
\text { DESCUBRIMIENTO } \\
\text { EN EL SB } \\
\end{array}$ \\
\hline $\begin{array}{l}\text { 1. Configuración en } \\
\text { Pubget, Knowledge Base } \\
\text { y Metasearch Content }\end{array}$ & & $\mathrm{X}$ & & X-Proceso complejo \\
\hline $\begin{array}{l}\text { 2. Disponibilidad de } \\
\text { documentos para cotejar } \\
\text { productos negociados y } \\
\text { su crecimiento en el } \\
\text { índice central }\end{array}$ & $X$ & & & $\begin{array}{ll}\text { X-Información } & \text { confusa } \\
\text { que no } & \text { permite } \\
\text { determinar el } & \text { alcance } \\
\text { real de la plataforma }\end{array}$ \\
\hline $\begin{array}{l}\text { 3. Acuerdos negociados } \\
\text { con una gran cantidad de } \\
\text { proveedores de } \\
\text { indexación y contenidos }\end{array}$ & $\mathrm{X}$ & & $X$ & \\
\hline $\begin{array}{l}\text { 4. Cantidad y diversidad } \\
\text { de las bases de datos } \\
\text { incluidas }\end{array}$ & & $\mathrm{X}$ & & $\begin{array}{l}\text { X-Formatos no incluidos } \\
\text { y alcance real limitado e } \\
\text { incierto }\end{array}$ \\
\hline $\begin{array}{l}\text { 5. Acceso a un índice } \\
\text { central }\end{array}$ & $X$ & & $X$ & \\
\hline 6. Acceso a WC & $\mathrm{X}$ & & $\mathrm{X}$ & \\
\hline $\begin{array}{ll}\text { 7. Integración } & \text { del } \\
\text { catálogo en línea } & \text { por } \\
\text { medio de WC } & \end{array}$ & $X$ & & & $\begin{array}{l}\text { X-Experiencia } \\
\text { incompleta }\end{array}$ \\
\hline $\begin{array}{ll}\text { 8. Acceso inmediato a un } \\
\text { número importante } & \text { de } \\
\text { repositorios } & \text { de } \\
\text { investigación } & \\
\end{array}$ & $\mathrm{X}$ & & $\mathrm{X}$ & \\
\hline $\begin{array}{l}\text { 9. Búsquedas en el } \\
\text { catálogo en línea en } \\
\text { tiempo real }\end{array}$ & $\mathrm{X}$ & & & $\begin{array}{l}\text { X-Experiencia } \\
\text { incompleta }\end{array}$ \\
\hline $\begin{array}{lr}10 . & \text { Acceso a repositorios } \\
\text { de } & \text { investigación } \\
\text { desarrollados } & \text { con }\end{array}$ & $\mathrm{X}$ & & $\mathrm{X}$ & \\
\hline
\end{tabular}




\begin{tabular}{|c|c|c|c|c|}
\hline RASGO & $\begin{array}{l}\text { FORTALEZA } \\
\text { INTRÍNSECA }\end{array}$ & $\begin{array}{l}\text { DEBILIDAD } \\
\text { INTRÍNSECA }\end{array}$ & $\begin{array}{ll}\text { FORTALECE } & \text { LA } \\
\text { EXPERIENCIA } & \text { DE } \\
\text { DESCUBRIMIENTO } \\
\text { EN EL SB }\end{array}$ & $\begin{array}{lr}\text { DEBILITA } & \text { LA } \\
\text { EXPERIENCIA } & \text { DE } \\
\text { DESCUBRIMIENTO } \\
\text { EN EL SB } \\
\end{array}$ \\
\hline \multicolumn{5}{|l|}{ CONTENTdm } \\
\hline 11. Búsquedas federadas & & $\mathrm{X}$ & & $\begin{array}{l}\text { X-Experiencia confusa } \\
\text { porque ralentizan las } \\
\text { búsquedas }\end{array}$ \\
\hline $\begin{array}{l}\text { 12. Búsqueda directa } \\
\text { sólo en algunas bases de } \\
\text { datos }\end{array}$ & & $\mathrm{X}$ & & X-Experiencia confusa \\
\hline $\begin{array}{l}\text { 13. Textos completos de } \\
\text { diversos proveedores }\end{array}$ & $\mathrm{X}$ & & & $\begin{array}{lr}\text { X-Experiencia ronfusa } \\
\text { porque pueden ser } \\
\text { redundantes }\end{array}$ \\
\hline $\begin{array}{l}\text { 14. Textos completos que } \\
\text { no se muestran en el } \\
\text { View now }\end{array}$ & & $\mathrm{X}$ & & X-Experiencia confusa \\
\hline $\begin{array}{l}\text { 15. Interfaz de búsqueda } \\
\text { que provee múltiples } \\
\text { opciones para delimitar } \\
\text { búsquedas y resultados }\end{array}$ & $\mathrm{X}$ & & & X-Experiencia confusa \\
\hline $\begin{array}{l}\text { 16. Interfaz de búsqueda } \\
\text { que provee herramientas } \\
\text { de valor añadido }\end{array}$ & $\mathrm{X}$ & & $\mathrm{X}$ & \\
\hline $\begin{array}{l}\text { 17. Interfaz de búsqueda } \\
\text { que provee opción de } \\
\text { lista A-Z de revistas y } \\
\text { ebooks configurados }\end{array}$ & $\mathrm{X}$ & & $\mathrm{X}$ & \\
\hline $\begin{array}{l}\text { 18. Interfaz de búsqueda } \\
\text { que provee versión } \\
\text { 'FBRizada' de los } \\
\text { registros bibliográficos }\end{array}$ & $\mathrm{X}$ & & $X$ & \\
\hline $\begin{array}{l}\text { 19. Neutralidad a la hora } \\
\text { de mostrar resultados de } \\
\text { las bases de datos }\end{array}$ & $\mathrm{X}$ & & $\mathrm{X}$ & \\
\hline $\begin{array}{l}\text { 20. Ranking superior de } \\
\text { los resultados que } \\
\text { provienen de WC }\end{array}$ & & $\mathrm{X}$ & & X-Experiencia confusa \\
\hline $\begin{array}{l}\text { 21. Fluctuaciones en la } \\
\text { relevancia de } \\
\text { resultados }\end{array}$ & & $\mathrm{X}$ & & X-Experiencia confusa \\
\hline $\begin{array}{l}22 . \quad \text { Contenidos no } \\
\text { recuperados por razones } \\
\text { técnicas }\end{array}$ & & $\mathrm{X}$ & & $\begin{array}{l}\mathrm{X} \text {-Experiencia } \\
\text { incompleta }\end{array}$ \\
\hline Total rasgos & 14 & 8 & 9 & 13 \\
\hline Porcentaje & $64 \%$ & $36 \%$ & $41 \%$ & $59 \%$ \\
\hline
\end{tabular}

Tabla I. Fortalezas y debilidades de la estructura de WCL que inciden en su eficacia.

La implementación de WCL en el SB ha permitido calibrar su estructura y los procesos de configuración necesarios para que la búsqueda en la 'ventanilla única' sea viable. Además, ha supuesto un ejercicio necesario para tener una idea más clara de su alcance. Todos los componentes de WCL se conjugan en una interfaz de búsqueda que tiene el potencial de explorar un universo bibliográfico muy amplio. WCL también dispone de muchas opciones de valor añadido que pueden ser de utilidad para usuarios avezados. Sin embargo, su eficacia guarda una estrecha relación con su complejidad y con las expectativas que despierta como plataforma de descubrimiento. 


\section{OPINIÓN DE LOS USUARIOS}

Durante el proceso de implementación de WCL se llevaron a cabo diversas reuniones con los bibliotecarios del SB y se les ofrecieron sesiones de capacitación para aclarar todos los detalles de la estructura de WCL necesarios para comprender su funcionamiento. No obstante, las críticas no se hicieron esperar. A pesar de los esfuerzos realizados para adoptar una herramienta, a todas luces, valiosa para simplificar la búsqueda en numerosas bases de datos y contenidos diversos, los bibliotecarios expresaban sus dudas e inconformidad con el rendimiento de WCL. La cantidad y relevancia de los resultados, a menudo inferior a la esperada, así como una estructura interna difícil de comprender, fueron las razones principales esgrimidas por muchos de los bibliotecarios para no incluir el metabuscador en sus clases de capacitación. Incluso los bibliotecarios que lo favorecían mostraban su desconfianza ante el comportamiento, a veces, errático de la plataforma.

Los usuarios, por otra parte, se enfrentaban a una nueva opción de búsqueda sobre la que tenían poca o ninguna información y a un producto novedoso que escondía una estructura compleja y poco intuitiva. No obstante, las estadísticas de uso recogidas por la plataforma reflejaban que el metabuscador se había convertido en una opción de búsqueda importante. Ya que la finalidad de suscribir un producto de esta naturaleza era facilitarles a los usuarios el acceso simultáneo a los contenidos de diversas bases de datos suscritas y gratuitas, era necesario conocer su opinión. Con este propósito, el SB llevó a cabo una encuesta entre sus usuarios durante el período comprendido entre el 4 de marzo y el 9 de abril de 2014. La encuesta se divulgó mediante una ventana emergente colocada en el portal del SB. El cuestionario, que incluyó 6 preguntas cerradas y 6 abiertas, fue contestado por 160 usuarios, principalmente, estudiantes de la Universidad de Puerto Rico, Recinto de Río Piedras. La mayoría de los encuestados indicó que usaba WCL semanalmente. De los usuarios que no lo habían usado nunca, el $64 \%$ atribuyó la falta de uso al desconocimiento de que existía tal herramienta (Ver Figuras 1-3).

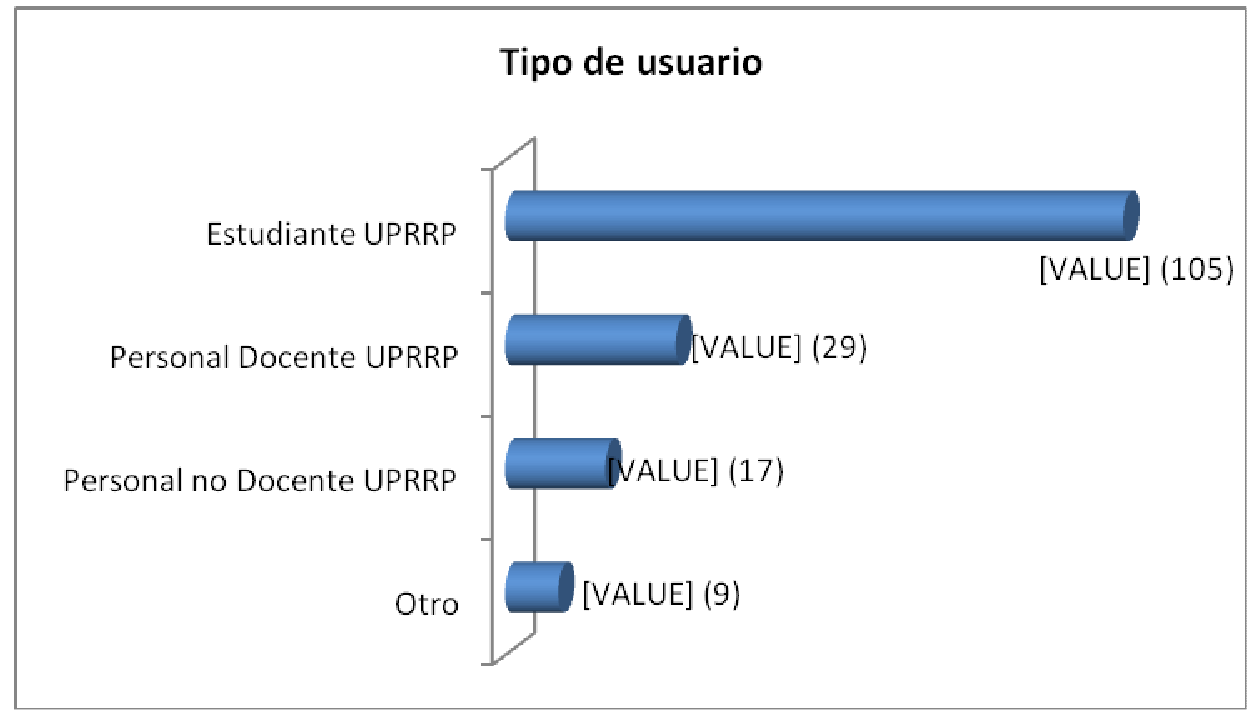

Figura 1. Tipo de usuario. 


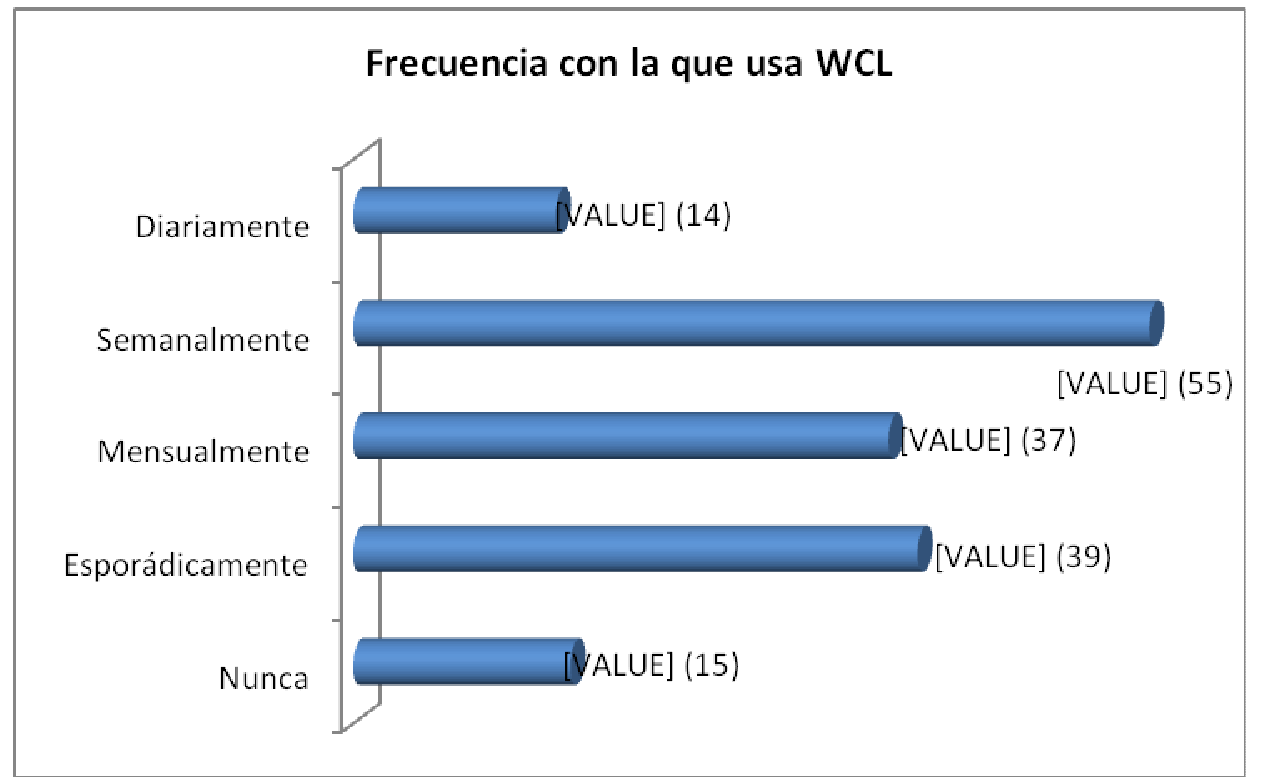

Figura 2. Frecuencia con la que usa WCL.

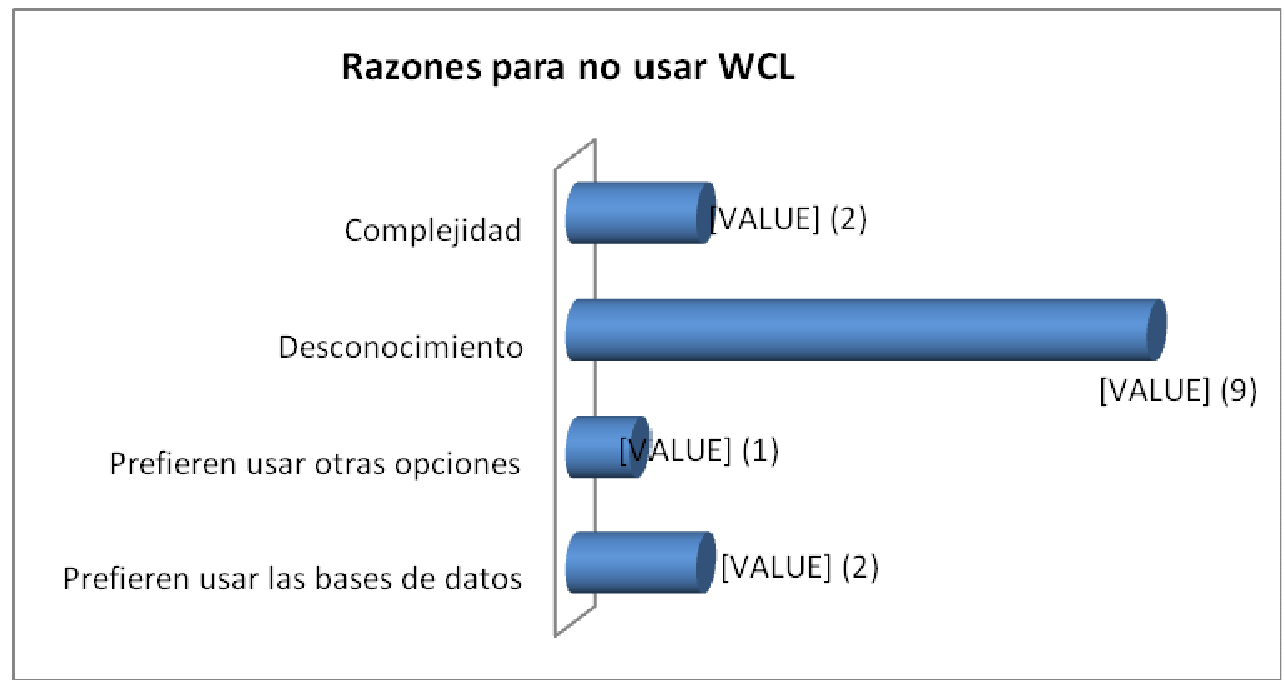

Figura 3. Razones para no usar WCL.

Se les pidió a los usuarios que comentaran sobre lo que más les gustaba y menos les gustaba de WCL. Se recibieron 225 comentarios sobre lo que más les gustaba y 165 comentarios sobre lo que menos les gustaba. Después de eliminar los comentarios irrelevantes, las repuestas restantes se clasificaron por tópicos. Se pudo inferir que lo que más les gustaba a los usuarios era su alcance (52\%) y su accesibilidad $(20 \%)$, ya que los comentarios más frecuentes hacían referencia a la variedad de fuentes de información que incluía y a que era una herramienta fácil de usar (Ver Figura 4). 


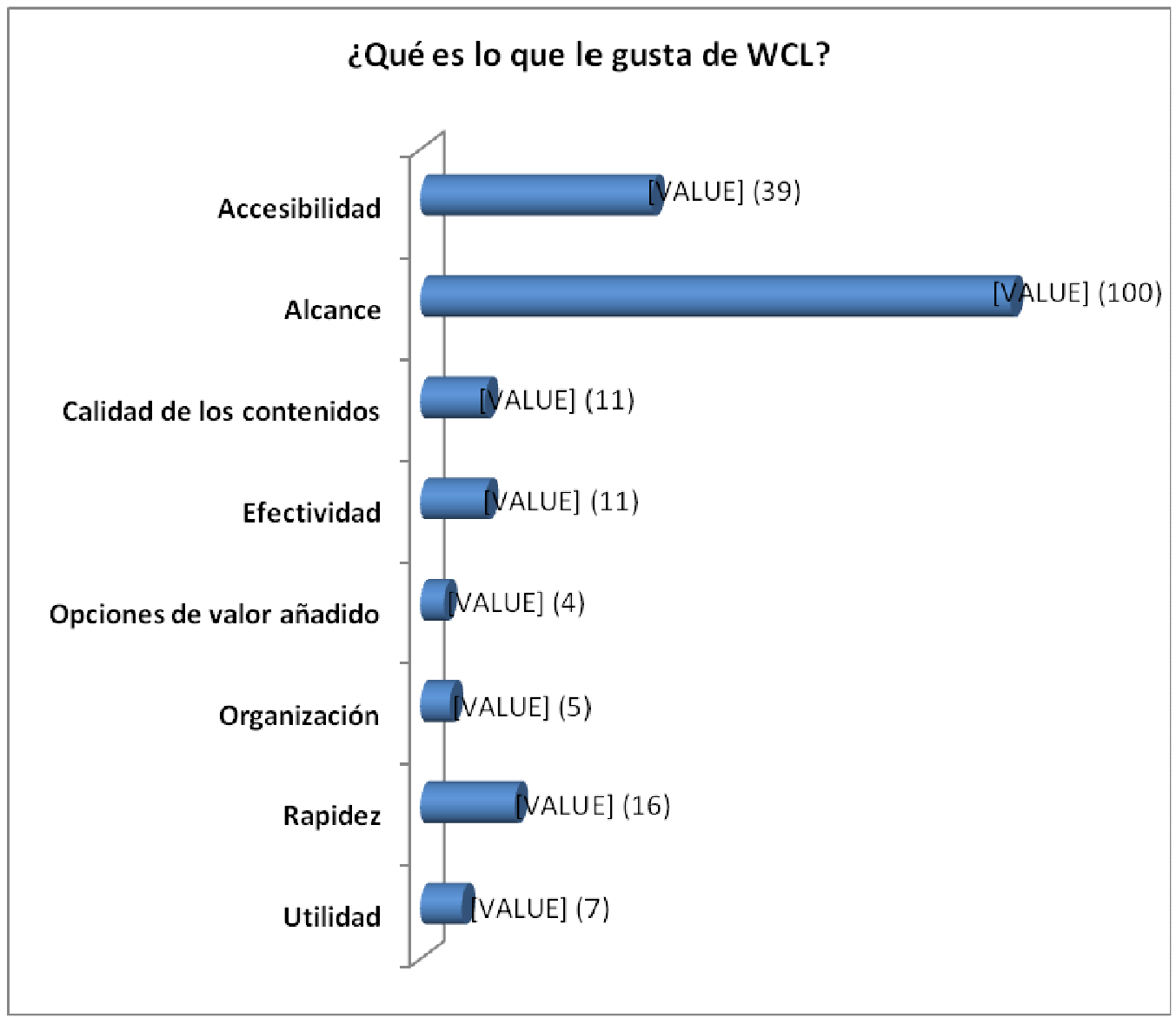

Figura 4. ¿Qué es lo que le gusta de WCL?

También se pudo inferir que lo menos que les gustaba a los usuarios era la complejidad del metabuscador (37\%) y su inefectividad (17\%), porque en los comentarios expresaban que era difícil navegar por la interfaz de búsqueda, que la cantidad de resultados obtenidos era menor que la esperada y que no podían acceder a algunos de los contenidos recuperados en las búsquedas. A pesar de que la mayoría de los usuarios anteriormente había valorado el alcance de WCL, en sus observaciones se quejan de que no incluya todas las bases de datos suscritas y de que no se pueda determinar cuáles incluye (16\%) (Ver Figura 5). 


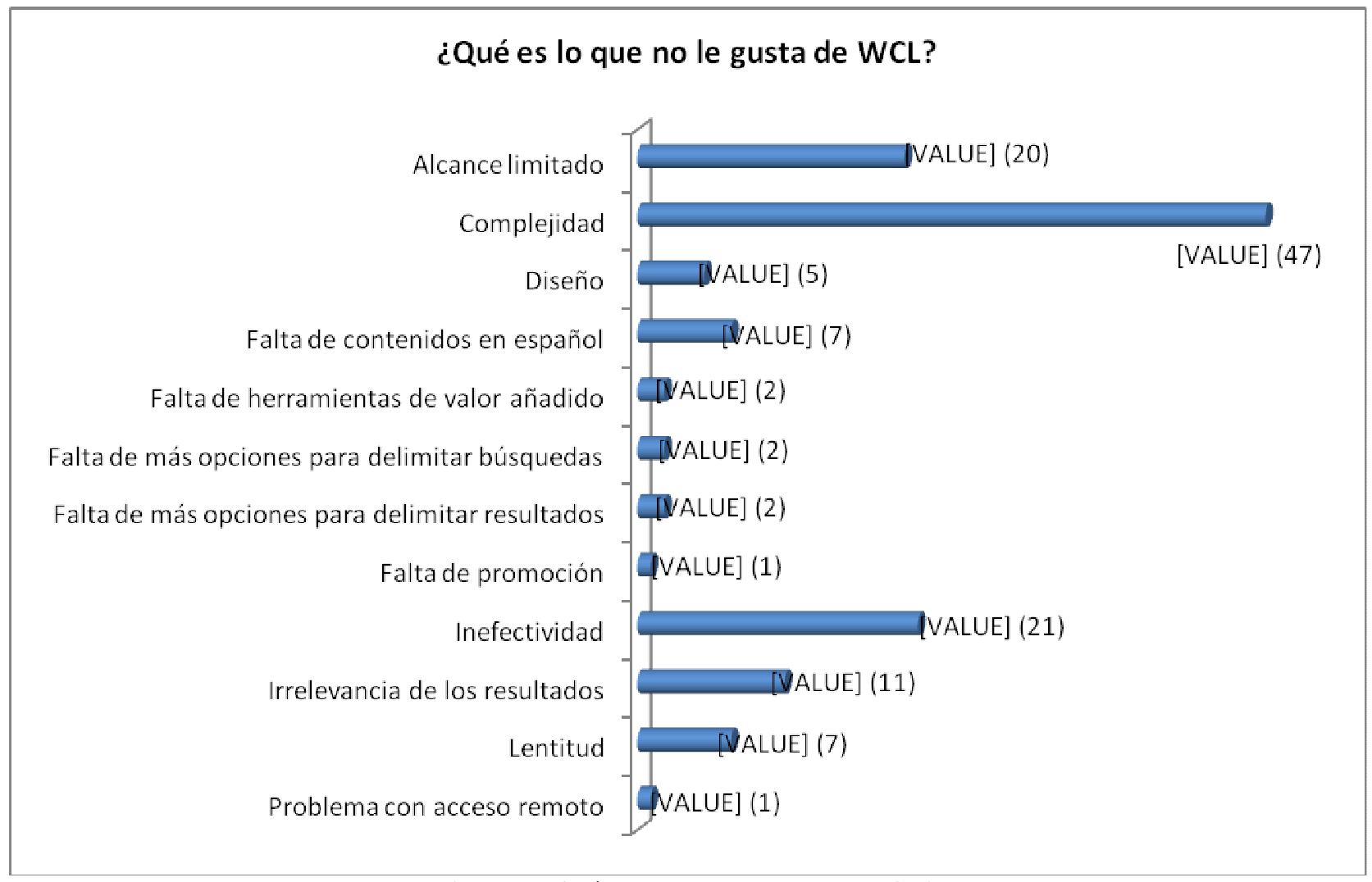

Figura 5. ¿Qué es lo que no le gusta de WCL?

Por otra parte, al preguntarles directamente a los encuestados si consideraban que WCL era fácil o difícil de usar, el 77\% indicó que era fácil de usar. La mayoría (65\%) también opinó que encontraba lo que buscaba 'Siempre' o 'Casi siempre'. En cuanto a si preferían buscar en el metabuscador o en las bases de datos, la mayoría (46\%) optó por ambas opciones o por la búsqueda directa en cada base de datos (34\%) (Ver Figuras 6-7).

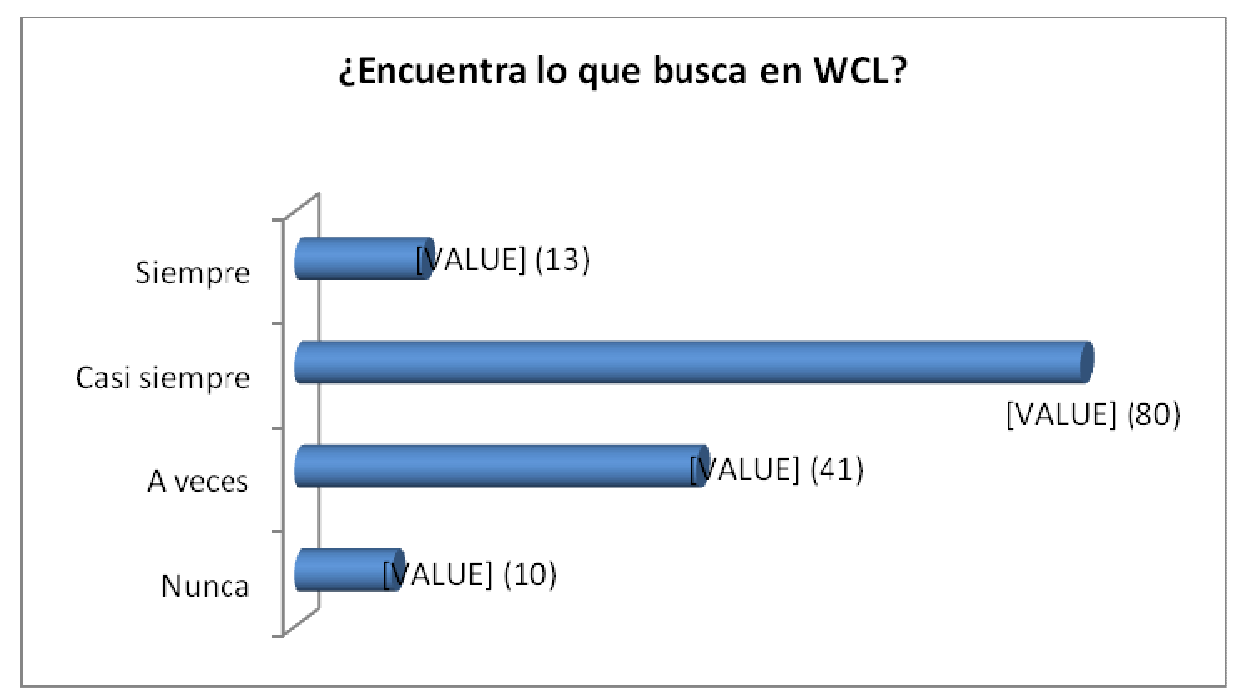

Figura 6. ¿Encuentra lo que busca en WCL? 


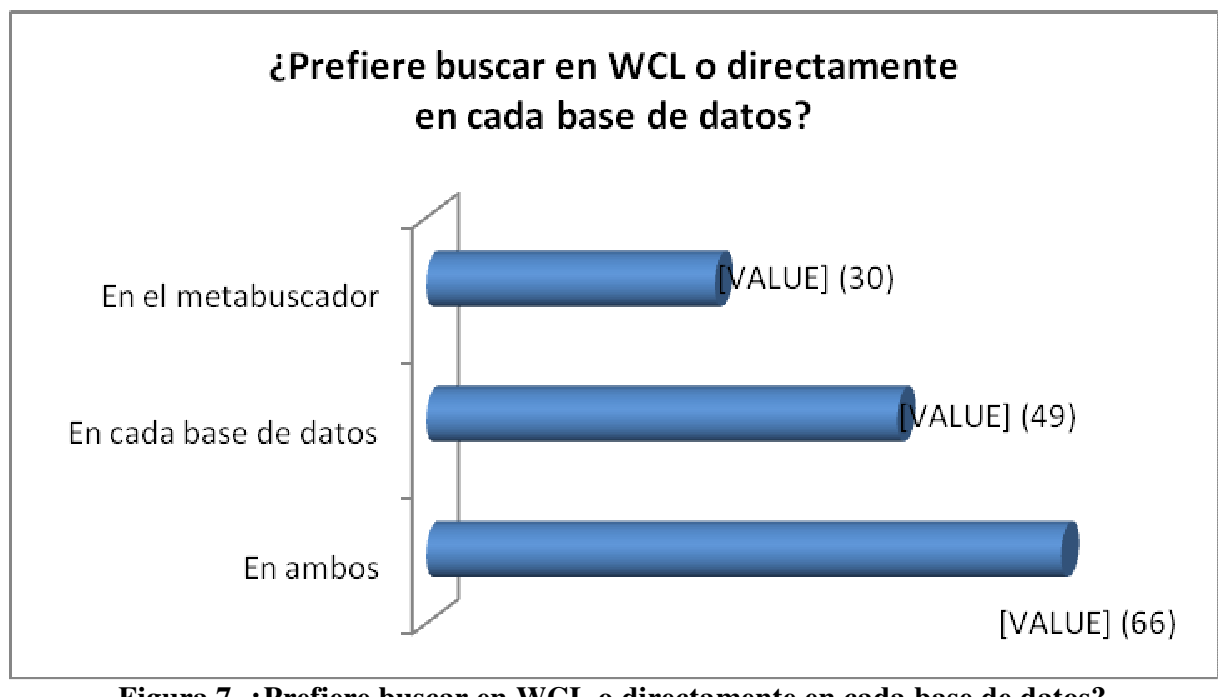

Figura 7. ¿Prefiere buscar en WCL o directamente en cada base de datos?

A los usuarios también se les preguntó qué le añadirían a WCL y qué eliminarían. Se recibieron 113 comentarios sobre lo que añadirían y 65 comentarios sobre lo que eliminarían. Nuevamente, para analizar y organizar las respuestas, se eliminaron los comentarios irrelevantes y luego se clasificaron las respuestas restantes por tópicos. De los comentarios se desprende que, en cuanto a los contenidos recuperados, el alcance del metabuscador debería ser mayor (25\%). En lo que se refiere a la interfaz de búsqueda, los comentarios apuntan a que se provean más opciones para delimitar las búsquedas $(23 \%)$ y a que la plataforma sea más intuitiva (12\%). Con respecto a las características que eliminarían de WCL, los pocos comentarios relevantes realizados aluden, mayormente, a su complejidad (Ver Figuras 8-9).

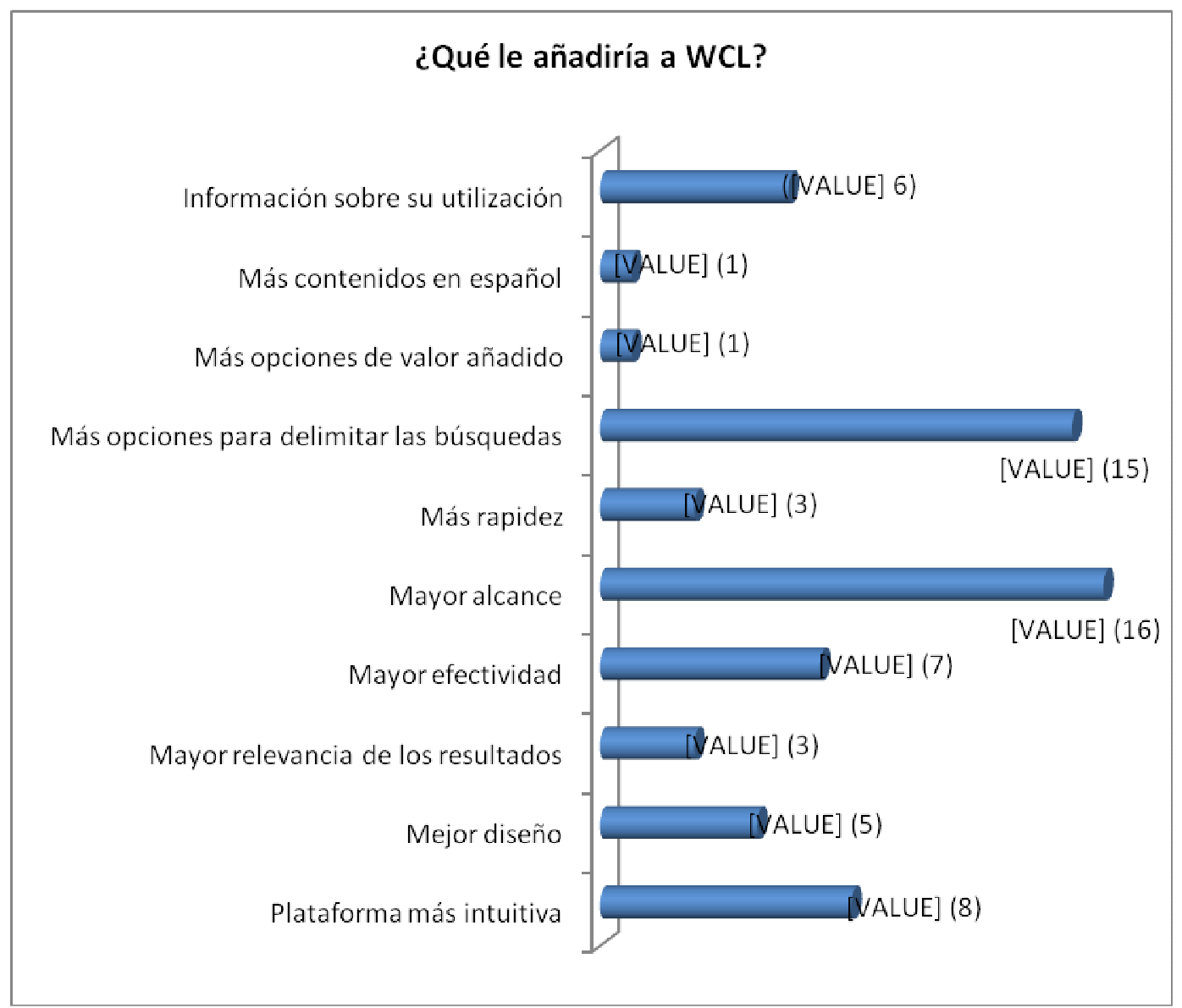

Figura 8. ¿Qué le añadiría a WCL? 


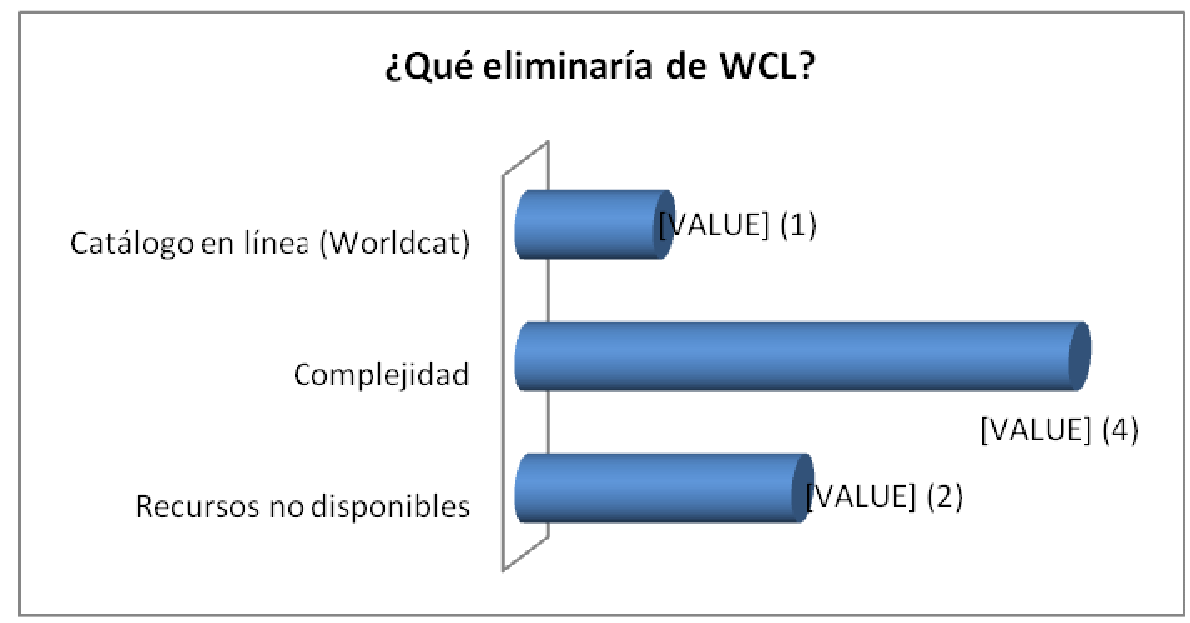

Figura 9. ¿Qué eliminaría de WCL?

Al preguntarles a los usuarios si recomendarían WCL a un amigo, el 86\% indicó que sí. Además, el 56\% de los comentarios ofrecidos al final de la encuesta fueron favorables (Ver Figura 10). A continuación se ofrecen algunos ejemplos:

- Buena herramienta. Una opción de mucho valor -buscar en el catálogo en línea y en las bases de datos a la vez-.

- Es una buena herramienta y tiene mucha utilidad. Si se mejoran los criterios de búsqueda y las formas de progresar en la búsqueda, sería la herramienta ideal.

- El sistema es muy bueno si sabes utilizarlo; en esto los talleres ayudan bastante.

- Herramienta muy útil para la investigación y para facilitar la publicación.

- Le he sacado buen uso al metabuscador. Logré encontrar un recurso raro y pedirlo a través de préstamo interbibliotecario. Todo esto aun cuando no pude lograr encontrarlo a través de Google.

- Como estudiante jornal asistente de investigación este recurso es imprescindible para mi trabajo. Este recurso ha agilizado lo que equivale a meses de trabajo.

- Es una excelente herramienta de búsqueda y ahorra mucho tiempo en el proceso de búsqueda e investigación.

- Lo usé hace mucho tiempo luego de un adiestramiento ofrecido en la Biblioteca Lázaro. Es un recurso estupendo y a mi entender poco conocido. Se debería realizar promoción agresiva directa a los estudiantes y hacia profesores para que la usen como herramienta.

- La biblioteca debería promocionar más el uso del metabuscador entre los estudiantes de sub-graduado [sic]. Esto facilitaría y maximizará la exposición a las bases de datos para sus tareas. Se entiende que actualmente muchos estudiantes no acuden a las bases de datos porque son muy complicadas para ellos o desconocen cuales corresponden a la disciplina que estudian.

- Espero que lo mantengan y que no lo eliminen de entre las bases de datos disponibles.

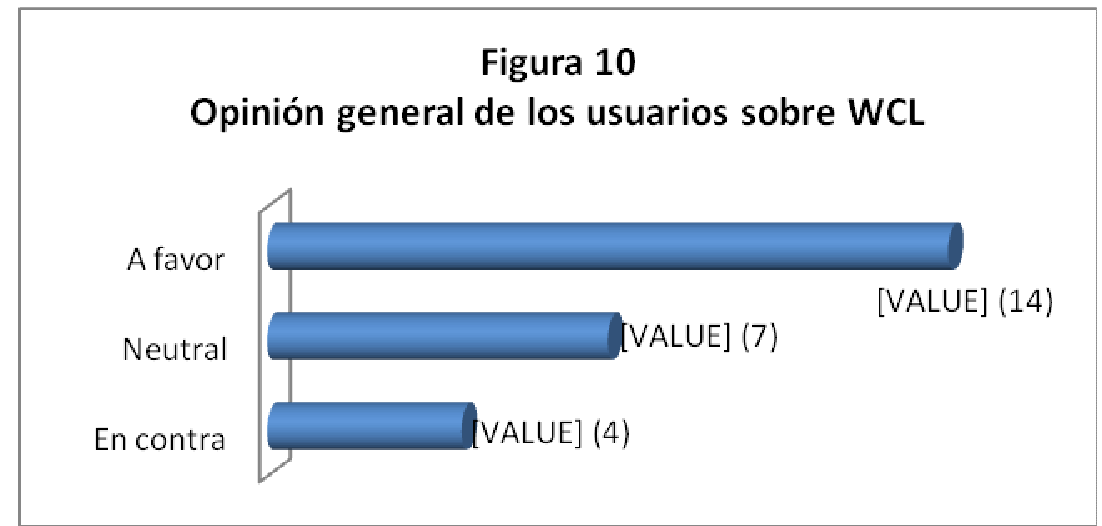

Figura 10. Opinión general de los usuarios sobre WCL. 


\section{CONCLUSIONES}

WCL es una herramienta compleja que tiene muchas fortalezas intrínsecas. Sin embargo, desde la óptica administrativa, no ha llenado las expectativas del SB porque, tiene una estructura compleja, requiere un proceso de configuración laborioso, existen dudas sobre su alcance real y no ofrece una experiencia de búsqueda lo suficientemente completa y transparente como para que se pueda considerar una plataforma de descubrimiento confiable.

En cambio, los resultados de la encuesta llevada a cabo entre usuarios del SB muestran la opinión de las personas que han usado el metabuscador espontáneamente, con poco o ningún conocimiento previo de su funcionamiento. Las respuestas indican que la gran mayoría de los participantes recomendaría WCL a un amigo y que lo considera una herramienta valiosa para la investigación. Las características que más aprecian de WCL son su alcance y accesibilidad. Lo que menos les gusta es su complejidad. Si bien la mayoría indica que casi siempre encuentra lo que busca, también hay comentarios que aluden a que el alcance, la efectividad y la relevancia de los resultados no son los esperados. Los usuarios desearían que hubiera más opciones para delimitar las búsquedas y que la plataforma fuera más intuitiva. Aunque en menor grado, expresan dudas sobre la deseabilidad de que WCL muestre información bibliográfica sobre recursos informativos que no están disponibles en el SB. La preferencia por la búsqueda, tanto en WCL como directamente en cada base de datos, podría ser un indicador de que los usuarios son conscientes de que el metabuscador es una herramienta útil, pero no sustituye a las bases de datos.

La implementación de WorldCat Local en el SB ha revelado las fortalezas y debilidades de un producto que aspira a simplificar el acceso a un mundo bibliográfico muy complejo. También ha demostrado que los usuarios valoran la disponibilidad de una herramienta que les permita agilizar la búsqueda de información.

\section{NOTA}

${ }^{1}$ WorldCat Local (WCL), ahora WorldCat Discovery, estuvo vigente en el SB desde junio de 2012 hasta junio de 2014 . La evaluación realizada se ha basado en la versión de la plataforma que estuvo disponible durante dicho período. Todos sus componentes fueron considerados antes de optar por otra plataforma de descubrimiento.

\section{BIBLIOGRAFÍA}

ALVITE DÍEZ, M.L. Redefiniendo el catálogo: expectativas de las interfaces de descubrimiento centradas en el usuario. Investigación Bibliotecológica, 2012, vol. 2, nº 56, p. 181-204.

ÁVILA GARCÍA, L.; ORTIZ REPISO, V. y RODRÍGUEZ MATEOS, D. Herramientas de descubrimiento: ¿una ventanilla única? Revista Española de Documentación Científica, 2015, vol. 38, $\mathrm{n}^{\circ} \quad 1$, doi: 10.3989/redc.2015.1.1178.

BADKE, W. The convenience factor in information seeking. Online Searcher, 2014, vol. 38, n ${ }^{\circ}$ 6, p. 68-70.

BOYD, J. et al. The one-box challenge: providing a federated search that benefits the research process. Serials Review, 2006, vol. 32, nº 4, p. 247-254.

BRAND, A.; DALY, F. y MEYERS, B. Metadata demystified: a guide for publishers. Hanover, Pennsylvania: NISO Press, Sheridan Press, 2003.

BREEDING, M. Library resource discovery products: context, library perspectives, and vendor positions. Library Technology Reports, 2014, vol. 50, $\mathrm{n}^{\mathrm{o}}$ 1, p. 1-58.

BREEDING, M. Libraries.org: a directory of libraries throughout the world. 2016. Disponible en: $<$ http://librarytechnology.org/libraries>. [Consulta: 17 de mayo de 2016].

BUTLER, A. y THOMPSON, L. Implementing discovery at the University of Alabama. The Southeastern Librarian, 2013, vol. 61, no 1, p. 44-47.

CONNAWAY, L.S. y RANDALL, K.M. Why the Internet is more attractive than the library. The Serials Librarian, 2013, vol. 64, n 1-4, p. 41-56.

CORNELL UNIVERSITY LIBRARY. Discovery and access: recommendation and report. Ithaca, N. Y.: Cornell University Library, 2011.

DARTMOUTH COLLEGE LIBRARY. An evaluation of Serial Solutions Summon as a discovery service for the Dartmouth College Library. Hanover, NH: Dartmouth College Library. 2009. Disponible en: $<$ http://www.dartmouth.edu/ library/admin/docs/Summon_Report.pdf?mswitch-redir=classic $>$. [Consulta: 17 de mayo de 2016].

DJENNO, M.; INSUA, G.; GREGORY, G.M. y BRANTLEY, J.S. Discovering usability: comparing two discovery systems at one academic library. Journal of Web Librarianship, 2014, vol. 8, $\mathrm{n}^{\mathrm{o}}$ 3, p. 263-285. 
FAWLEY, N. y KRYSAK, N. Learning to love your discovery tool: strategies for integrating a discovery tool in faceto-face, synchronous, and asynchronous instruction. Public Services Quarterly, 2014, vol. 10, n 4, p. 83-301.

GEORGAS, H. Google vs. the library: student preferences and perceptions when doing research using Google and a federated search tool. Portal: Libraries and the Academy, 2013, vol. 13, n 2, p. 165-185.

GEORGAS, H. Google vs. the library (Part II): student search patterns and behaviors when using Google and a federated search tool. Portal: Libraries and the Academy, 2014, vol. 14, nº 4, p. 503-532.

GLASSER, S. Broken links and failed access: how KBART, IOTA, and PIE-J can help. Library Resources \& Technical Services, 2011, vol. 56, $\mathrm{n}^{\mathrm{O}} 1$, p. 14-23.

GOODSETT, M. Discovery search tools: a comparative study. Reference Reviews, 2014, vol. 28, nº 6, p. 2-8.

HERRRERA, G. Metasearching and beyond: implementation experiences and advice from an academic library. Information Technology \& Libraries, 2007, vol. 24, $\mathrm{n}^{\circ}$ 2, p. 44-52.

KELLEY, M. Coming into focus: web-scale discovery services face growing need for best practices. Library Journal, 2012, vol. $137, \mathrm{n}^{\mathrm{O}} 17$, p. 34-40.

KING, D. Many libraries have gone to federated searching to win users back from Google: is it working? Journal of Electronic Resources Librarianship, 2008, vol. 20, n 4, p. 213-227.

KULP, C.; MCCAIN, C. y SCRIVENER, L. Teaching outside the box: ARL librarian's integration of the "One-Box" into student instruction. College \& Research Libraries, 2014, vol. 75, nº 3, p. 298-308.

NFAIS. Survey comparison on discovery service participation and perceptions. Annapolis, MD.: NFAIS, 2014. Disponible en: <https://nfais.memberclicks.net/assets/docs/BestPractices/2014_surveycomparisons_disc.pdf>. [Consulta: 17 de mayo de 2016].

NISO. Understanding metadata. Bethseda, MD: NISO, 2004. Disponible en: $<$ http://www.niso.org/publications/press/UnderstandingMetadata.pdf $>$. [Consulta: 17 de mayo de 2016].

OCLC. Databases and collections in WorldCat Local. 2016a. Disponible en: <https://www.oclc.org/worldcatlocal/content/dblist.en.html>. [Consulta: 17 de mayo de 2016].

OCLC. WorldCat knowledge base. 2016b. Disponible en: <https://www.oclc.org/knowledge-base.en.html>. [Consulta: 17 de mayo de 2016].

PARRY, M. As researchers turn to Google, libraries navigate the messy world of discovery tools. The Chronicle of Higher Education, 2014, vol. 60, n ${ }^{\circ} 32$, p. 18.

POPP, M.P. y DALLIS, D. Planning and implementing resource discovery tools in academic libraries. Hershey, PA: IGI Global, 2012.

PRESCOTT, L. y ERWAY, R. Single search: the quest for the Holy Grail. Dublin, Ohio: OCLC, 2011.

SPINK, A. et al. Searching the web: the public and their queries. Journal of the American Society for Information Science and Technology, 2001, vol. 52, n 3, p. 226-234.

STRYKOWSKI, J. Advanced vs. basic search: digital perception and library learning. The Journal of Academic Librarianship, 2015, vol. 41, n ${ }^{\circ}$ 5, p. 689-691.

TENNANT, R. The right solution: federated search tools. Library Journal, 2003, vol. 128, n 11, p. 28-30.

TRAINOR, C. y PRICE, J. Rethinking library linking: breathing new life into open url. Library Technology Reports, 2010, vol. 46, no 7, p. 5-35.

VAUGHAN, J. Web scale discovery services. Library Technology Reports, 2011, vol. 47, nº 1, p. 5-61. 